\title{
DETERMINACIÓN DE LA CALIDAD Y LA PRODUCCIÓN DE SORGO NEGRO FORRAJERO (Sorghum almum) EN EDADES PARA ENSILAR1
}

\author{
Carlos Boschini Figueroa², Jorge Elizondo Salazar ${ }^{2}$
}

\begin{abstract}
RESUMEN
Determinación de la calidad y la producción de sorgo negro forrajero (Sorghum almum) en edades para ensilar. En la Estación Experimental "Alfredo Volio Mata", Universidad de Costa Rica se evaluó la composición y la producción de materia seca y de los contenidos nutricionales por área de sorgo forrajero, en edades entre 91 y 161 días de rebrote, y explorar opciones de cosecha para ensilar. Los muestreos se iniciaron a la edad de 91 días de rebrote y continuaron cada 14 días hasta 161 días de edad. La producción de biomasa fue medida y se determinó el contenido de materia seca, proteína cruda, cenizas totales, fibra neutro detergente y sus componentes. Los contenidos de materia seca y fibra neutro detergente aumentaron conforme aumentó la edad de las plantas, a razón de $0,19 \%$ /día en hojas y de 0,26 \%/día en los tallos, para un 0,22 \%/día en la planta entera. El rendimiento de materia verde alcanzó el máximo a los 135 días, la parte foliar a 121 días y los tallos a 144 días. La producción máxima de materia seca, proteína cruda y de fibra neutro detergente por hectárea se obtuvo entre los 130 y 135 días de rebrote. La mejor calidad se encontró a los 91 días, con 12\% de materia seca y $14 \%$ de proteína cruda. A partir de esta edad, la acumulación de materia seca se incrementó a una tasa de $62 \mathrm{~kg} / \mathrm{ha}$ /día (la concentración en $2 \%$ cada 10 días), de lo cual $48 \mathrm{~kg}$ fueron de fibra neutro detergente y un promedio de $2 \mathrm{~kg}$ de lignina. El contenido de proteína cruda disminuyó un $1 \%$ cada 10 días.
\end{abstract}

Palabras claves: Sorghum almum, calidad, producción,

\begin{abstract}
Quality and fodder yield of forage black sorghum (Sorghum almum) for silage in mature ages. The study was carried out to determine the chemical composition and production yield of dry matter and nutritional content per area in shoots 91 to 161 days old, and to explore the options for harvest silage. The study took place at the Alfredo Volio Mata Experimental Station of the University of Costa Rica. The first samples were taken at 91 days and were re-taken every 14 days until they were 161 days old. Biomass production was measured and the content of dry matter, crude protein, ashes, neutral detergent fiber increased as the maturity of the plants increased, to a rate of $0.19 \% /$ day in leaves and $0.26 \%$ /day in stems, for a $0.22 \%$ /day in the whole plant. The yield of green matter reached its maximum at 135 days, the leaves at 121 days, and the stems at 144 days. The maximum production of dry matter, crude protein and neutral detergent fiber per hectare was obtained from shoots of 130 to 135 days old. The best quality was found at 91 days, with $12 \%$ of dry matter and $14 \%$ crude protein. From that age on, the accumulation of dry matter increased at a rate of 62 $\mathrm{kg} / \mathrm{ha} /$ day (a concentration of $2 \%$ every 10 days), of which 48 $\mathrm{kg}$ were of neutral detergent fiber and an average of $2 \mathrm{~kg}$ of lignin. The content of crude protein decreased $1 \%$ every 10 days.
\end{abstract}

Key words: Sorghum almum, quality, yield, silage. ensilaje.

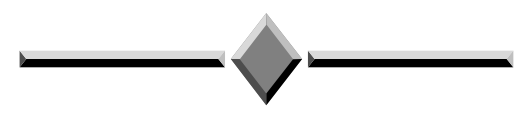

\section{INTRODUCCIÓN}

El cultivo de sorgo negro forrajero para la producción de forraje se ha venido extendiendo en la franja centroamericana, particularmente entre Panamá y Honduras. Si bien esta especie forrajera no es permanente, el cultivo perdura de tres a cinco años, sometido a frecuencias de corte regulares cada 70 a 150 días, con prácticas de manejo adecuadas (Corrales 1986; Hernández 1986; Alfaro 1988). Se siembra en explotaciones intensivas de producción de forraje, para suministrarlo picado en fresco o como reserva de forraje para la época seca

1 Recibido: 23 de agosto, 2004. Aceptado: 16 de diciembre, 2004. Inscrito en la Vicerrectoría de Investigación, No. 737-97-006

2 Estación Experimental Alfredo Volio Mata. Facultad de Agronomía. Universidad de Costa Rica. Correo electrónico: boschini@cariari.ucr.ac.cr 
conservado mediante ensilaje (Villegas 1990). Lo ideal en un cultivo forrajero de corte, es el establecimiento de una frecuencia de cosecha constante. Sin embargo, debido al régimen estacional de lluvias en Centroamérica y con frecuencia la aparición de cambios inesperados en la distribución de los volúmenes de lluvia, los finqueros alargan las frecuencias de corte, en consecuencia se acumulan y envejecen en pie las reservas forrajeras de los cultivos de corte. El sorgo negro forrajero es un material resistente que permite la conservación con facilidad, debido al alto contenido de sustancias solubles, siempre que se sigan los procedimientos de elaboración de ensilaje adecuados. La disponibilidad de ese producto permite una mejor alimentación del ganado en los períodos secos del trópico y posee gran habilidad para recuperarse de la sequía (Owen y Moline 1970).

Los estudios en forraje fresco, a partir de las ocho semanas de crecimiento, indican un contenido de proteína cruda de $18 \%$ y de fibra neutro detergente de $63 \%$ y conforme se desarrolla la planta, disminuye la proteína a $12 \%$ y la fibra aumenta a $70 \%$ a los tres meses, con contenidos de materia seca inferior a $20 \%$, llegando a $8,7 \%$ de proteína cruda y $75 \%$ de fibra neutro detergente a los cuatro meses (Amador et al. 2000). Entre ocho y 12 semanas de edad, la degradabilidad potencial de la materia seca disminuye de 80 a $77 \%$ y de la pared celular baja de 69 a 61\% (Jiménez 1995), conservando constante una fracción soluble de 23 a $25 \%$ de la materia seca presente. A los 120 y 150 días de rebrote, se reportan valores de 21 y $16,5 \%$ de materia seca en la fracción soluble, con degradabilidades de la materia seca superiores a 58\% en 24 horas de incubación ruminal (Boschini y Amador 2001), lo cual indica la potencial capacidad del sorgo negro forrajero para ser ensilado en edades tardías de corte, superiores a los cuatro meses, cuando la planta entera alcanza contenidos de materia seca cercanos a $25 \%$ o superiores, condición que favorece la optimización el proceso de fermentación láctica durante el ensilaje (McDonald 1981).

El presente trabajo se realizó con el objetivo de determinar la composición química y la producción de materia seca y de los contenidos nutricionales por hectárea, tanto en la planta y como en sus partes componentes, a partir de los 91 días y hasta los 161 días de crecimiento del rebrote, con el fin de explorar diferentes opciones óptimas de cosecha en estado maduro.

\section{MATERIALES Y MÉTODOS}

El experimento se llevó a cabo en la Estación Experimental "Alfredo Volio Mata" de la Universidad de Costa Rica, ubicada a $1.542 \mathrm{msnm}$, con una precipita- ción media anual de $2.050 \mathrm{~mm}$, distribuida en los meses de mayo a noviembre. La temperatura media es de $19,5{ }^{\circ} \mathrm{C}$ y la humedad relativa media es de $84 \%$. El suelo es de origen volcánico, clasificado como Typic Distrandepts (Vásquez 1982). Se caracteriza por una profundidad media, con buen drenaje natural y una fertilidad media. El terreno empleado tuvo un $\mathrm{pH}$ de 6,0. La zona se tipifica ecológicamente como bosque húmedo montano bajo (Tosi 1970, citado por Vásquez 1982).

Se prepararon $5200 \mathrm{~m}^{2}$ de terreno, con arada y rastrea. Se fertilizó con una cantidad equivalente a $368 \mathrm{~kg}$ de la fórmula $\left(\mathrm{N}_{2}, \mathrm{P}_{2} \mathrm{O}_{5}, \mathrm{~K}_{2} \mathrm{O}\right)$ 10-30-10. Se volvió a rastrear y se surcó a una distancia de $70 \mathrm{~cm}$. La siembra se efectuó el 21 de mayo del 2003, con una cantidad equivalente de $19 \mathrm{~kg} / \mathrm{ha}$ de semilla de sorgo negro forrajero ( $84 \%$ semilla pura germinable). La semilla fue mezclada con tierra seca fina, en una relación de 1:1 $\mathrm{v} / \mathrm{v}$, distribuida manualmente a chorro continuo. A los 42 días después de la siembra se aplicaron $45,5 \mathrm{~kg} / \mathrm{ha}$ de nitrógeno en forma de nitrato de amonio. El cultivo fue observado cada 14 días hasta alcanzar los primeros 120 días de crecimiento, edad en la cual el cultivo estuvo establecido y se realizó el primer corte de uniformización en todo el terreno sembrado. El rebrote fue observado durante los siguientes 14 días. El terreno cultivado se dividió en 24 parcelas de $200 \mathrm{~m}^{2}$ cada una, entre las cuales se distribuyeron al azar las seis edades de muestreo: 91, 105,119, 133, 147 y 161 días, con cuatro repeticiones cada una, empleando un diseño irrestrictamente al azar 42 días después de la cosecha de uniformización se aplicaron 45,5 kg/ha de nitrógeno (nitrato de amonio).

A los 91 días de edad se realizó el primer muestreo de plantas y los siguientes se efectuaron cada 14 días hasta el último a los 161 días de edad. Cada muestreo se realizó con base en la cosecha de toda la parcela para medir el peso en fresco y estimar la producción de biomasa por unidad de área. Las plantas fueron cortadas a tres $\mathrm{cm}$ sobre el nivel de suelo. Conforme cada parcela fue cosechada, se fueron extrayendo muestras de las plantas enteras en forma aleatoria, separando tallos y hojas. Dentro de la fracción de tallos, se incluyeron las panojas que emergieron a partir de los 119 días. Las partes de la planta fueron pesadas y secadas en un horno a $60{ }^{\circ} \mathrm{C}$ durante 48 horas, hasta alcanzar un peso constante. Posteriormente, se molieron y se procedió a determinar el contenido de materia seca en una estufa a $105^{\circ} \mathrm{C}$, la concentración de proteína cruda por el método Kjeldall y la cenizas totales (AOAC 2002). La fibra neutro detergente (FND), la fibra ácido detergente (FAD) y la lignina fueron analizadas con el método descrito por Goering y Van Soest (1970). Los valores de hemicelulosa y celulosa se obtuvieron por diferencia de las fracciones fibrosas correspondientes. Los datos 
fueron analizados con el PROC ANOVA del paquete estadístico SAS (1985). En las fuentes de variación que resultaron significativas, se aplicó la separación de medias con la prueba de Duncan.

\section{RESULTADOS}

La composición química de la hoja, el tallo y la planta entera medidos en el sorgo negro forrajero, a diferentes edades de crecimiento, se presentan en el Cuadro 1. En las Figuras 1, 3 y 5 se observa la tendencia que tuvo la concentración de materia seca, proteína cruda y fibra neutro detergente en la hoja, el tallo y en la planta entera, conforme aumentó la edad de la planta. En las Figuras 2, 4 y 6 se muestra la evolución de las fracciones de la fibra neutro detergente en la hoja, el tallo y en la planta entera, a través de la maduración de la planta. En hojas la concentración de materia seca y de proteína cruda fue mayor que en tallos entre los 91 y 161 días, mientras que el tallo mostró una mayor proporción de pared celular a partir de los 105 días. En hojas y tallos la concentración de materia seca se incrementó en forma lineal después de los 91 días, a razón de $0,19 \%$ y $0,26 \% /$ día, respectivamente, con un valor global en planta entera de $0,22 \%$ diario. La concentra- ción de pared celular tuvo una tendencia cuadrática, con un máximo a los 125 días en hoja y 135 días en ta1lo. La fracción de fibra ácida en la hoja mantuvo una tendencia lineal de crecimiento, con un aumento sostenido de 0,049\%/día, mientras que en el tallo presentó incrementos decrecientes hasta alcanzar un máximo a los 135 días, a partir del cual decreció.

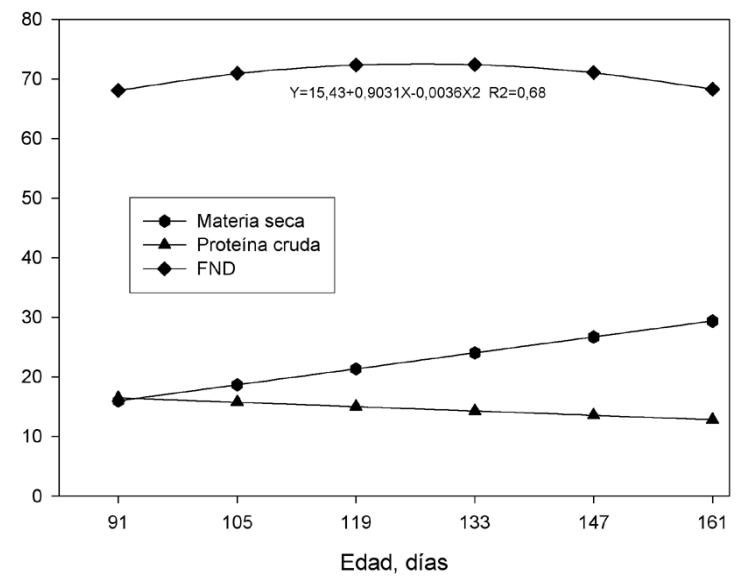

Figura 1. Contenido de MS, PC y FND en la hoja a diferentes edades de rebrote en sorgo negro forrajero. Estación Experimental "Alfredo Volio Mata". Ochomogo, Cartago, Costa Rica. 2003.

Cuadro 1. Composición química de la hoja, tallo y planta entera de sorgo negro forrajero en diferentes edades de crecimiento. Estación Experimental "Alfredo Volio Mata”. Ochomogo, Cartago, Costa Rica.. 2003.

\begin{tabular}{|c|c|c|c|c|c|c|c|c|c|}
\hline $\begin{array}{l}\text { Parte } \\
\text { planta }\end{array}$ & $\begin{array}{l}\text { Edad } \\
\text { días }\end{array}$ & $\begin{array}{c}\text { MS } \\
\%\end{array}$ & $\begin{array}{c}\text { PC } \\
\%\end{array}$ & $\begin{array}{c}\text { FND } \\
\%\end{array}$ & $\begin{array}{c}\text { FAD } \\
\%\end{array}$ & $\underset{\%}{\text { Hemi }}$ & $\begin{array}{c}\text { Cel } \\
\%\end{array}$ & $\underset{\%}{\mathbf{L i g}}$ & $\begin{array}{c}\text { Cenizas } \\
\%\end{array}$ \\
\hline \multirow[t]{6}{*}{ Hoja } & 91 & $16,74 \mathrm{c}$ & $16,72 \mathrm{a}$ & $67,78 \mathrm{c}$ & $36,55 \mathrm{c}$ & $31,24 \mathrm{~b}$ & $32,89 \mathrm{bc}$ & $3,65 \mathrm{e}$ & $10,87 \mathrm{ab}$ \\
\hline & 105 & $18,04 \mathrm{c}$ & $16,00 \mathrm{ab}$ & $70,66 \mathrm{bc}$ & $39,27 \mathrm{~b}$ & $31,39 \mathrm{~b}$ & $34,47 \mathrm{a}$ & $4,81 \mathrm{~cd}$ & $11,05 \mathrm{ab}$ \\
\hline & 119 & $21,09 \mathrm{bc}$ & $14,68 \mathrm{bc}$ & $74,39 \mathrm{a}$ & $37,78 \mathrm{bc}$ & 36,61 a & $33,35 \mathrm{ab}$ & $4,43 \mathrm{de}$ & $10,57 \mathrm{ab}$ \\
\hline & 133 & $23,35 \mathrm{bc}$ & $13,88 \mathrm{c}$ & $70,39 \mathrm{bc}$ & $38,32 \mathrm{~b}$ & $32,08 \mathrm{~b}$ & $32,84 \mathrm{bc}$ & $5,48 \mathrm{~cd}$ & $10,76 \mathrm{ab}$ \\
\hline & 147 & $27,77 \mathrm{ab}$ & $13,09 \mathrm{c}$ & $71,21 \mathrm{~b}$ & $39,25 \mathrm{~b}$ & $31,97 \mathrm{~b}$ & $32,38 \mathrm{bc}$ & $6,86 \mathrm{~b}$ & $9,75 a b$ \\
\hline & 161 & $29,20 \mathrm{a}$ & $13,51 \mathrm{c}$ & $68,58 \mathrm{bc}$ & $41,24 \mathrm{a}$ & $27,35 \mathrm{c}$ & $31,79 \mathrm{c}$ & $9,44 \mathrm{a}$ & $9,29 \mathrm{c}$ \\
\hline \multirow[t]{6}{*}{ Tallo } & 91 & $8,63 \mathrm{~d}$ & $11,06 \mathrm{a}$ & $65,17 \mathrm{~d}$ & $40,59 \mathrm{c}$ & 24,58 & $37,66 \mathrm{c}$ & $2,93 \mathrm{c}$ & $13,82 \mathrm{a}$ \\
\hline & 105 & $9,89 \mathrm{~d}$ & $8,34 \mathrm{~b}$ & $72,54 \mathrm{c}$ & $47,22 \mathrm{~b}$ & 25,32 & $43,17 \mathrm{~b}$ & $4,05 \mathrm{c}$ & $13,49 \mathrm{a}$ \\
\hline & 119 & $14,49 \mathrm{c}$ & $5,95 \mathrm{c}$ & $79,24 \mathrm{ab}$ & $51,51 \mathrm{a}$ & 27,72 & $46,12 \mathrm{a}$ & $5,38 \mathrm{~b}$ & $9,40 \mathrm{~b}$ \\
\hline & 133 & $20,24 \mathrm{~b}$ & $4,97 \mathrm{~cd}$ & $80,91 \mathrm{ab}$ & $53,28 \mathrm{a}$ & 27,63 & $46,05 \mathrm{a}$ & $7,24 \mathrm{a}$ & $7,31 \mathrm{c}$ \\
\hline & 147 & $22,19 b$ & $4,28 \mathrm{~d}$ & $76,49 \mathrm{bc}$ & $50,46 \mathrm{ab}$ & 26,04 & $43,59 \mathrm{ab}$ & 6,86 a & $6,08 \mathrm{c}$ \\
\hline & 161 & $25,47 \mathrm{a}$ & $4,83 \mathrm{~cd}$ & $76,32 \mathrm{bc}$ & $49,68 \mathrm{ab}$ & 26,63 & $41,78 \mathrm{~b}$ & $7,89 \mathrm{a}$ & $6,39 \mathrm{c}$ \\
\hline \multirow[t]{6}{*}{ Entera } & 91 & $12,07 \mathrm{~d}$ & 14,37 a & $66,75 \mathrm{~d}$ & $38,23 \mathrm{c}$ & 28,52 & $34,88 \mathrm{c}$ & $3,35 \mathrm{~d}$ & $12,08 \mathrm{a}$ \\
\hline & 105 & $12,76 \mathrm{~d}$ & $12,19 \mathrm{~b}$ & $71,64 \mathrm{c}$ & $43,25 \mathrm{~b}$ & 28,39 & $38,82 \mathrm{~b}$ & $4,44 \mathrm{c}$ & $12,25 \mathrm{a}$ \\
\hline & 119 & $17,01 \mathrm{c}$ & $10,02 \mathrm{c}$ & $77,16 \mathrm{a}$ & $45,22 \mathrm{ab}$ & 31,94 & $40,24 \mathrm{ab}$ & $4,98 \mathrm{c}$ & $9,88 \mathrm{~b}$ \\
\hline & 133 & $21,19 \mathrm{~b}$ & $7,98 \mathrm{~d}$ & $77,34 \mathrm{a}$ & $48,24 \mathrm{a}$ & 29,10 & $41,58 \mathrm{a}$ & $6,66 \mathrm{~b}$ & $8,49 \mathrm{c}$ \\
\hline & 147 & $23,75 \mathrm{ab}$ & $7,23 \mathrm{~d}$ & $74,74 \mathrm{ab}$ & $46,69 \mathrm{a}$ & 28,05 & $39,79 \mathrm{ab}$ & $6,89 \mathrm{~b}$ & $7,33 \mathrm{~d}$ \\
\hline & 161 & $26,53 \mathrm{a}$ & $7,19 \mathrm{~d}$ & $74,28 \mathrm{bc}$ & $47,48 \mathrm{a}$ & 26,80 & $39,14 \mathrm{ab}$ & $8,34 \mathrm{a}$ & $7,19 \mathrm{~d}$ \\
\hline
\end{tabular}

a,b,c,d,e muestran diferencias significativas $\mathrm{p}<0,05$ entre edades,

$\mathrm{MS}=$ materia seca, $\mathrm{PC}=$ proteína cruda, $\mathrm{FND}=$ fibra neutro detergente, $\mathrm{FAD}=$ fibra ácido detergente, Hemi= hemicelulosa, Cel= celulosa, Lig= Lignina. 


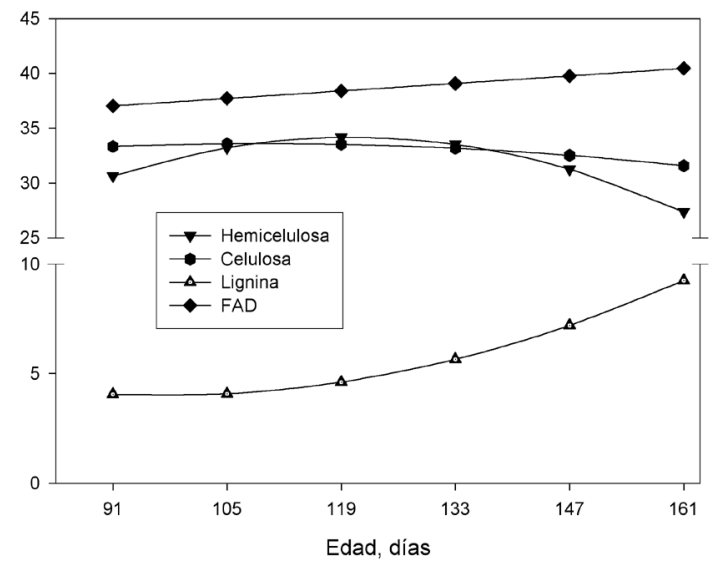

Figura 2. Contenido de FAD, hemicelulosa, celulosa y lignina en la hoja a diferentes edades de rebrote en sorgo negro forrajero. Estación Experimental "Alfredo Volio Mata”. Ochomogo, Cartago, Costa Rica. 2003.

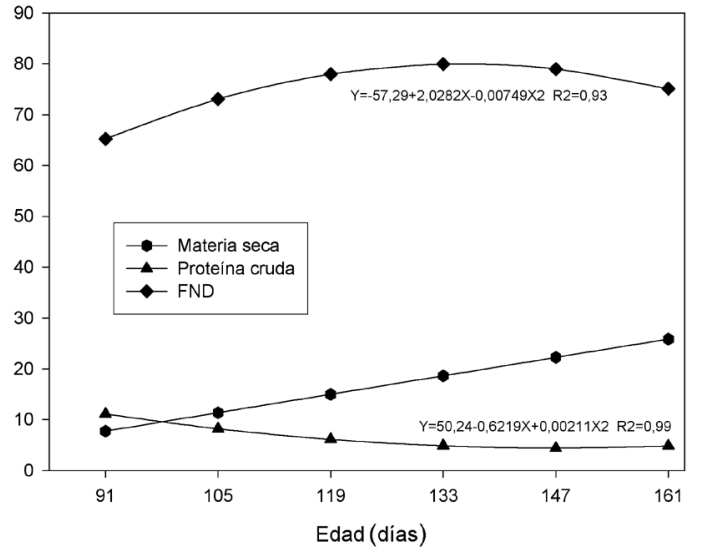

Figura 3. Contenido de MS, PC y FND en el tallo a diferentes edades de rebrote en sorgo negro forrajero. Estación Experimental "Alfredo Volio Mata". Ochomogo, Cartago, Costa Rica. 2003.

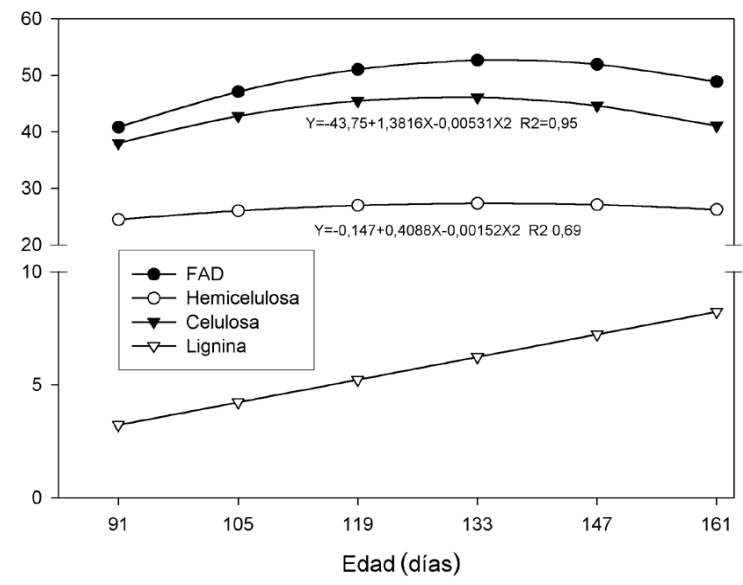

Figura 4. Contenido de FAD, hemicelulosa, celulosa y lignina en el tallo a diferentes edades de rebrote sorgo negro forrajero. Estación Experimental "Alfredo Volio Mata”. Ochomogo, Cartago, Costa Rica. 2003.

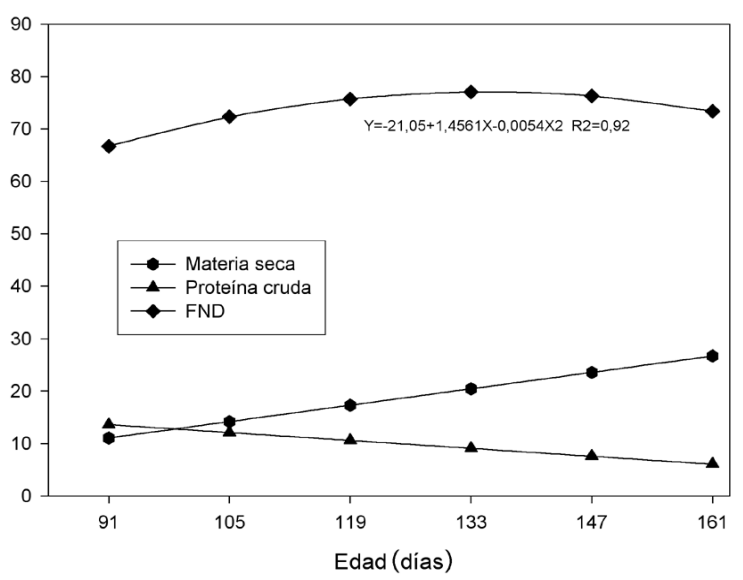

Figura 5. Contenido de MS, PC y FND en la planta entera a diferentes edades de rebrote en sorgo negro forrajero. Estación Experimental "Alfredo Volio Mata”. Ochomogo, Cartago, Costa Rica. 2003.

En la planta entera hubo una acumulación límite de 49\% a los 140 días. Otros dos componentes de la pared celular, la hemicelulosa y la celulosa, mostraron en hoja y tallo un comportamiento cuadrático, con máximos de hemicelulosa a los 125 días en hoja y a 135 días en los tallos. La acumulación de celulosa fue máxima a los 108 días en la hoja y a 130 días en el tallo. La lignificación de la pared celular de las hojas y los tallos fue creciendo a partir del día 91, con incrementos diarios cada vez mayores en las hojas y en forma constante en el tallo, mostrando en la planta entera una ganancia media diaria de $0,07 \%$ de lignina respecto al contenido de materia seca.

La producción por hectárea de materia verde, materia seca, las proteínas y fibras, presentes en la hoja, el

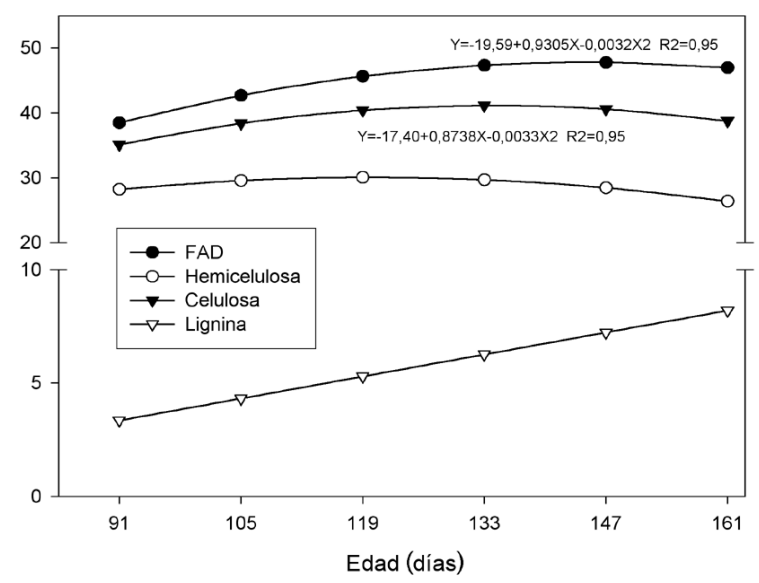

Figura 6. Contenido de FAD, hemicelulosa, celulosa y lignina en la planta entera a diferentes edades de rebrote en sorgo negro forrajero. Estación Experimental "Alfredo Volio Mata”. Ochomogo, Cartago, Costa Rica. 2003. 
tallo y la planta entera, a través de las diferentes edades de crecimiento, se observan en el Cuadro 2. El rendimiento de forraje verde alcanzó el máximo desarrollo entre los 91 y 161 días. En la hoja el pico de producción se dio a los 121 días y en el tallo a los 144 días, siendo absoluto en la planta entera a los 135 días. El rendimiento por hectárea de materia seca, proteína y pared celular presentes en las hojas (Figuras 7 y 8 ) fue

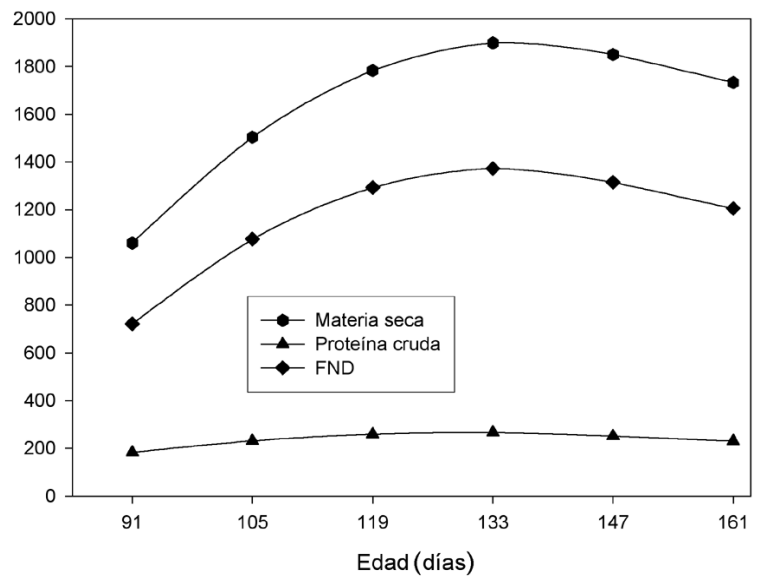

Figura 7. Producción de MS, PC y FND en hoja a diferentes edades de rebrote en sorgo negro forrajero. Estación Experimental "Alfredo Volio Mata". Ochomogo, Cartago, Costa Rica. 2003.

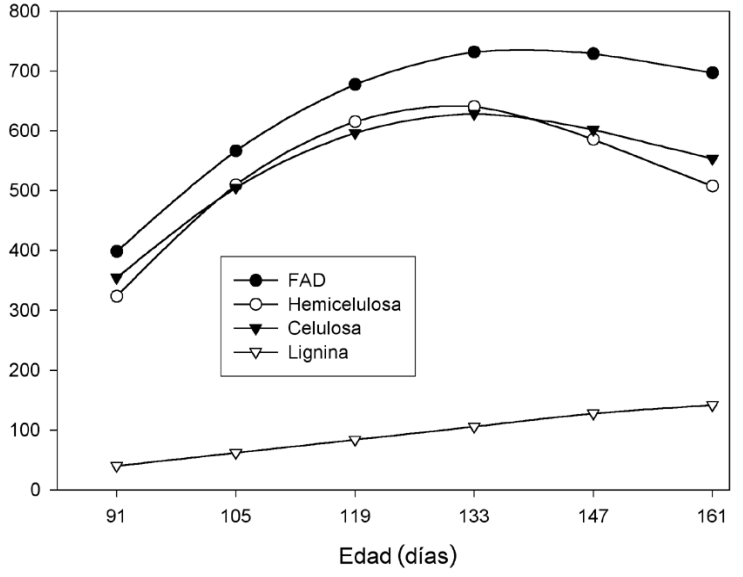

Figura 8. Producción de FAD, hemicelulosa, celulosa y lignina en hoja a diferentes edades de rebrote en sorgo negro forrajero. Estación Experimental "Alfredo Volio Mata”. Ochomogo, Cartago, Costa Rica. 2003.

también máximo entre los 130 y 135 días. En el tallo, la materia seca y los componentes proteicos y fibrosos (Figuras 9 y10) continuaron acumulándose en forma lineal, a razón de 53,77, 1,70 y 42,46 kg/ha/día, respectivamente. En conjunto, la planta entera (Figuras 11 y 12) mostró un rendimiento de masa y fibra acumulada en forma lineal, con incrementos diarios de $62 \mathrm{~kg} / \mathrm{ha} \mathrm{de}$

Cuadro 2. Producción de materia verde, seca y nutrientes por hectárea en la hoja, tallo y planta entera de sorgo negro forrajero en diferentes edades de crecimiento. Estación Experimental “Alfredo Volio Mata”. Ochomogo, Cartago, Costa Rica. 2003.

\begin{tabular}{|c|c|c|c|c|c|c|c|c|c|c|}
\hline $\begin{array}{l}\text { Parte } \\
\text { planta }\end{array}$ & $\begin{array}{l}\text { Edad } \\
\text { días }\end{array}$ & $\begin{array}{c}\text { MV } \\
\text { kg/ha }\end{array}$ & $\begin{array}{c}\text { MS } \\
\text { kg/ha }\end{array}$ & $\begin{array}{c}\text { PC } \\
\mathrm{kg} / \mathrm{ha}\end{array}$ & $\begin{array}{l}\text { FND } \\
\mathrm{kg} / \mathrm{ha}\end{array}$ & $\begin{array}{l}\text { FAD } \\
\text { kg/ha }\end{array}$ & $\begin{array}{l}\text { Hemi } \\
\text { kg/ha }\end{array}$ & $\begin{array}{c}\text { Cel } \\
\text { kg/ha }\end{array}$ & $\begin{array}{c}\text { Lig } \\
\text { kg/ha }\end{array}$ & $\begin{array}{c}\text { Cenizas } \\
\text { kg/ha }\end{array}$ \\
\hline \multirow[t]{6}{*}{ Hoja } & 91 & $6786 \mathrm{bc}$ & $1134 \mathrm{~b}$ & $191 \mathrm{~b}$ & $771 \mathrm{~b}$ & $416 \mathrm{c}$ & $355 \mathrm{c}$ & $374 \mathrm{~b}$ & $42 \mathrm{~d}$ & $123 \mathrm{~b}$ \\
\hline & 105 & 6786 bc & $1227 \mathrm{~b}$ & $194 \mathrm{~b}$ & $869 \mathrm{~b}$ & $481 \mathrm{bc}$ & $387 \mathrm{c}$ & $423 \mathrm{~b}$ & $58 \mathrm{~cd}$ & $136 \mathrm{~b}$ \\
\hline & 119 & $9643 \mathrm{a}$ & $2030 \mathrm{a}$ & $298 \mathrm{a}$ & $1512 \mathrm{a}$ & $767 \mathrm{a}$ & $745 \mathrm{a}$ & $677 \mathrm{a}$ & $90 \mathrm{bcd}$ & $214 \mathrm{a}$ \\
\hline & 133 & $8929 a b$ & $2087 \mathrm{a}$ & $291 \mathrm{ab}$ & $1469 \mathrm{a}$ & 799 a & $670 a b$ & $685 \mathrm{a}$ & $113 \mathrm{~b}$ & $224 \mathrm{a}$ \\
\hline & 147 & $5357 \mathrm{c}$ & $1476 \mathrm{ab}$ & $192 \mathrm{~b}$ & $1049 a b$ & $579 a b$ & $469 \mathrm{bc}$ & $478 a b$ & $101 \mathrm{bc}$ & $144 \mathrm{~b}$ \\
\hline & 161 & $6071 \mathrm{c}$ & $1783 a b$ & $239 \mathrm{ab}$ & $1228 a b$ & $730 \mathrm{ab}$ & $498 \mathrm{bc}$ & $565 \mathrm{ab}$ & $165 \mathrm{a}$ & $166 \mathrm{ab}$ \\
\hline \multirow[t]{6}{*}{ Tallo } & 91 & $9643 \mathrm{c}$ & 814 e & $89 \mathrm{c}$ & $535 \mathrm{~d}$ & $336 \mathrm{~d}$ & $199 \mathrm{~d}$ & $311 \mathrm{~d}$ & $25 \mathrm{~d}$ & $113 \mathrm{~b}$ \\
\hline & 105 & $12322 \mathrm{bc}$ & $1232 \mathrm{de}$ & $102 \mathrm{c}$ & $898 \mathrm{~cd}$ & $583 \mathrm{~cd}$ & $314 \mathrm{~cd}$ & $533 \mathrm{~cd}$ & $50 \mathrm{~d}$ & $164 \mathrm{~b}$ \\
\hline & 119 & $16072 \mathrm{abc}$ & $2348 \mathrm{~cd}$ & $138 \mathrm{bc}$ & $1868 \mathrm{bc}$ & $1222 \mathrm{bc}$ & $646 \mathrm{bc}$ & $1090 \mathrm{bc}$ & $131 \mathrm{bc}$ & $217 \mathrm{ab}$ \\
\hline & 133 & 20714 a & $4217 \mathrm{ab}$ & $214 a b$ & 3419 a & $2257 \mathrm{a}$ & $1161 \mathrm{a}$ & $1950 \mathrm{a}$ & $307 \mathrm{ab}$ & 313 a \\
\hline & 147 & $13215 \mathrm{bc}$ & $2959 \mathrm{bc}$ & $128 \mathrm{c}$ & $2267 \mathrm{bc}$ & $1496 \mathrm{bc}$ & $771 \mathrm{bc}$ & $1291 \mathrm{bc}$ & $206 \mathrm{bc}$ & $179 \mathrm{~b}$ \\
\hline & 161 & $18572 \mathrm{ab}$ & $4674 \mathrm{a}$ & $225 \mathrm{a}$ & 3564 a & $2316 \mathrm{a}$ & $1248 \mathrm{a}$ & 1947 a & 369 a & $298 \mathrm{a}$ \\
\hline \multirow[t]{6}{*}{ Entera } & 91 & $16429 \mathrm{c}$ & 1949 c & $280 \mathrm{c}$ & $1305 \mathrm{c}$ & $752 \mathrm{c}$ & $554 \mathrm{c}$ & $685 c$ & $67 \mathrm{e}$ & $236 \mathrm{c}$ \\
\hline & 105 & 19107 bc & $2459 \mathrm{c}$ & $296 \mathrm{c}$ & $1767 \mathrm{c}$ & $1065 \mathrm{c}$ & $701 \mathrm{~b}$ & $956 \mathrm{c}$ & $109 \mathrm{de}$ & $300 \mathrm{bc}$ \\
\hline & 119 & $25714 a b$ & $4378 \mathrm{~b}$ & $436 \mathrm{abc}$ & $3380 \mathrm{~b}$ & $1989 \mathrm{~b}$ & $1391 \mathrm{bc}$ & $1768 \mathrm{~b}$ & $221 \mathrm{~cd}$ & $431 \mathrm{ab}$ \\
\hline & 133 & $29643 \mathrm{a}$ & $6303 \mathrm{a}$ & $505 \mathrm{a}$ & $4888 \mathrm{a}$ & $3056 \mathrm{a}$ & $1832 \mathrm{a}$ & $2636 \mathrm{a}$ & $420 \mathrm{ab}$ & $537 \mathrm{a}$ \\
\hline & 147 & $18571 \mathrm{bc}$ & $4435 \mathrm{~b}$ & $321 \mathrm{bc}$ & $3316 \mathrm{~b}$ & $2076 \mathrm{~b}$ & $1240 \mathrm{ab}$ & $1769 \mathrm{~b}$ & $307 \mathrm{bc}$ & $323 \mathrm{bc}$ \\
\hline & 161 & $24643 a b c$ & $6456 \mathrm{a}$ & $465 \mathrm{ab}$ & $4792 a b$ & $3046 \mathrm{a}$ & $1746 \mathrm{a}$ & $2512 \mathrm{ab}$ & $535 \mathrm{ab}$ & $464 \mathrm{ab}$ \\
\hline
\end{tabular}

a,b,c,d,e muestran diferencias significativas $\mathrm{p}<0,05$ entre edades.

$\mathrm{MV}=$ materia verde, $\mathrm{MS}=$ materia seca, $\mathrm{PC}=$ proteína cruda, $\mathrm{FND}=$ fibra neutro detergente, $\mathrm{FAD}=$ fibra ácido detergente,

Hemi $=$ hemicelulosa, $\mathrm{Cel}=$ celulosa, $\mathrm{Lig}=$ Lignina. 


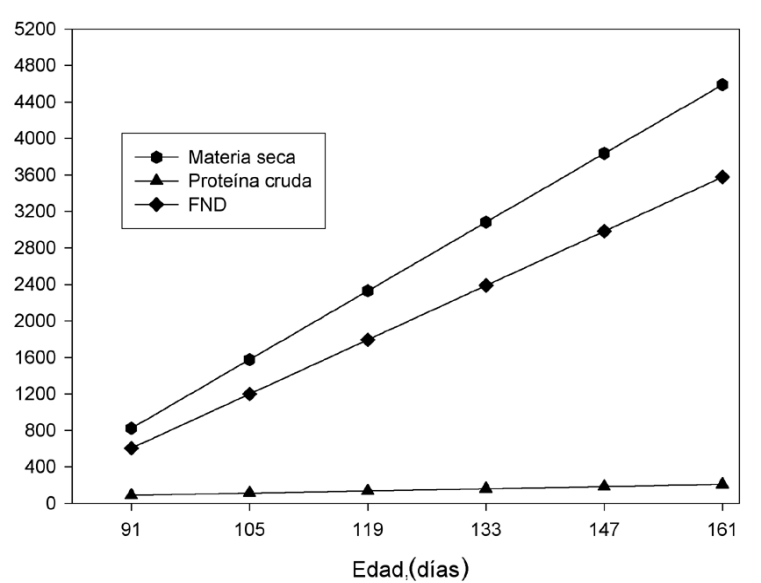

Figura 9. Producción de MS, PC y FND en tallo a diferentes edades de rebrote en sorgo negro forrajero. Estación Experimental "Alfredo Volio Mata". Ochomogo, Cartago, Costa Rica. 2003.

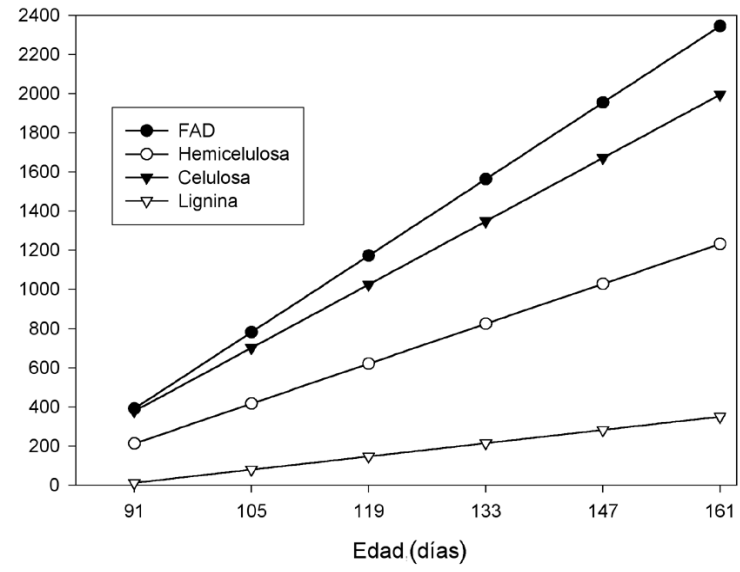

Figura 10. Producción de FAD, hemicelulosa, celulosa y lignina en tallo a diferentes edades de rebrote en sorgo negro forrajero. Estación Experimental "Alfredo Volio Mata”. Ochomogo, Cartago, Costa Rica. 2003.

materia seca y $48 \mathrm{~kg} / \mathrm{ha}$ de pared celular. La acumulación por hectárea de proteína cruda crece lentamente hasta los 145 días y posteriormente decrece poco a poco, encontrándose en concentraciones cercanas al $7 \%$ a los 161 días. La producción por hectárea de los componentes de la pared celular: fibra ácida, hemicelulosa y celulosa presentes en la hoja (Figura 8) se dio hasta los 130-139 días y decreció posteriormente, mientras que en el tallo (Figura 10) continuó la acumulación en tasas de 27,91, 14,55 y 23,09 kg/ha/día, respectivamente. En la planta entera (Figura 12) se encontró un comportamiento lineal similar a lo presentado en el tallo. La lignina acumulada en la fibra producida por hectá-

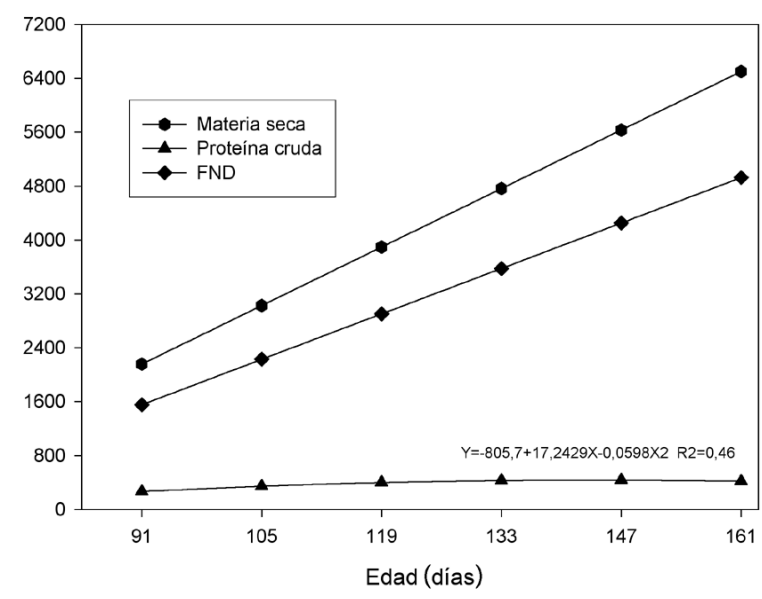

Figura 11. Producción de MS, PC y FND en planta entera a diferentes edades de rebrote en sorgo negro forrajero. Estación Experimental "Alfredo Volio Mata". Ochomogo, Cartago, Costa Rica. 2003.

rea, tuvo un crecimiento constante en hojas y tallos, a razón de 1,56 y $4,84 \mathrm{~kg} / \mathrm{ha} /$ día respectivamente, para un incremento en el rendimiento de la planta entera de $6,39 \mathrm{~kg} / \mathrm{ha} / \mathrm{día}$.

La concentración de cenizas en la hoja sufrió pequeñas diferencias entre 91 y 147 días maduración, diferenciándose estadísticamente a los 161 días $(\mathrm{P} \leq 0,05)$. En el tallo, los contenidos de cenizas evidenciaron marcadas diferencias $(\mathrm{P} \leq 0,01)$ en tres grupos de edad diferentes, en 91 y 105 días entre 13,5 y 13,8\%, a 119 días se encontró un 9,4\% y entre las edad de 133 a 161 días

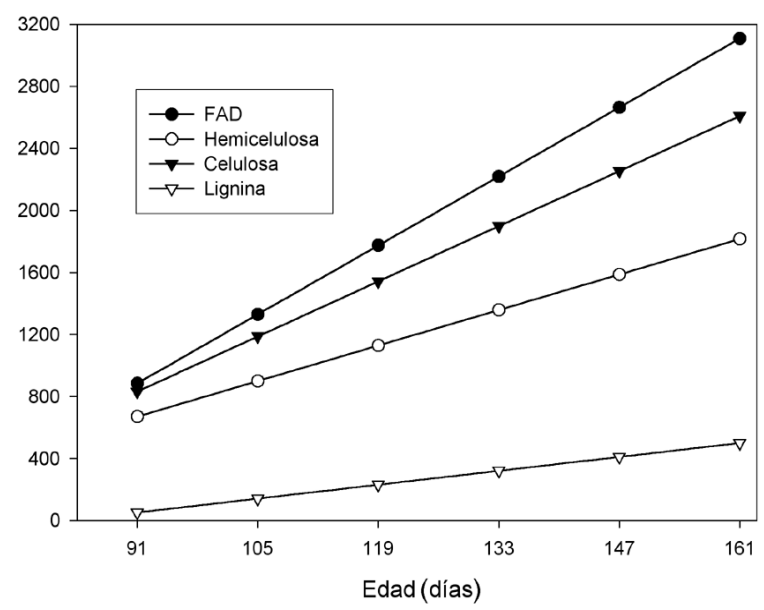

Figura 12. Producción de FAD, hemicelulosa, celulosa y lignina en tallo a diferentes edades de rebrote en sorgo negro forrajero. Estación Experimental "Alfredo Volio Mata”. Ochomogo, Cartago, Costa Rica. 2003. 
con el nivel más bajo, entre 6,4 y 7,3\%. La mayor acumulación de cenizas por hectárea se presentó a los 133 días tanto en hoja como en tallo, en una relación de 2:5 a 3:5, con una acumulación total de $537 \mathrm{~kg} / \mathrm{ha}$ de cenizas en la planta entera.

\section{DISCUSIÓN}

Los resultados muestran el valor nutricional y el rendimiento potencial del sorgo negro forrajero en edades tardías de rebrote, cuando el cultivo está por alcanzar o ha alcanzado la madurez fisiológica. Los forrajes en esta etapa son generalmente usados para su conservación como ensilaje (Peñagaricano et al. 1973; Boschini y Elizondo 2003). Si el interés fuese la máxima cosecha de materia seca, debe tomarse en cuenta que la producción de materia seca sigue creciendo en la planta entera hasta los 161 días, estacionándose el crecimiento masal a los 135 días en las hojas y posteriormente, decaer el volumen foliar en forma paulatina, arrastrando una pérdida de proteína y de fibra neutro detergente a partir de los 130 y 135 días, respectivamente. Sin embargo, se observó que la tendencia de la producción de materia seca en los tallos y en la planta entera es de acumulación continua, en forma lineal $(53,77 \mathrm{y}$ $62,01 \mathrm{~kg} / \mathrm{ha} /$ día respectivamente), y similar comportamiento se observa en las Figuras 10 y 12 con la pared celular, con un definitivo estacionamiento de la producción de proteína, señal de que el cultivo envejece después de los 135 días. Sin embargo, a los 161 días se observó un aumento en la producción de materia seca, proteína cruda y pared celular en la hoja de 21, 24 y $17 \%$, y en el tallo de 58, 76 y 57\%, respectivamente, a consecuencia de la emergencia de un nuevo rebrote en la corona; dándole al cultivo un rejuvenecimiento aparente. Similares valores de caída fueron reportados por Amador y Boschini (2000) a la edad de 136 días, con un aumento de la producción a los 150 días y un leve incremento en la relación hoja:tallo, con un aumento neto de $10,5 \%$ en la concentración de fibra neutro detergente a los 133 días (aumento relativo de 15,9\%) y una caída de $6,5 \%$ de proteína cruda (disminución relativa de $44,5 \%$ ) en el mismo periodo, reforzando la tesis de que el cultivo envejece en términos reales. Amador et al. (2000) reportó un valor de $78 \%$ de fibra neutro detergente a los 136 días con un contenido de 7,7\% de proteína cruda. La mejor calidad se encontró a los 91 días, con $12 \%$ de materia seca y $14 \%$ de proteína cruda, previo a la floración, reportada esta a los 108 días. El envejecimiento después de los 91 días se produjo con una ganancia diaria de $0,22 \%$ de materia seca y una pérdida diaria de $0,11 \%$ proteína cruda, representando un aumento de $2 \%$ en la concentración de materia seca y una pérdida de $1 \%$ en la concentración de proteína cru- da cada 10 días, con una ganancia de $62 \mathrm{~kg} / \mathrm{ha} /$ día de materia seca, de la cual $48 \mathrm{~kg}$ fueron fibra neutro detergente, conteniendo esta fracción un aumento promedio diario de $2 \mathrm{~kg}$ de lignina, haciendo que la materia seca cosechada y consumida por los animales sea más resistente al ataque bacterial durante el proceso de digestión ruminal (Van Soest 1982), en consecuencia se tendría menos aprovechamiento de la energía y de la proteína disponible para la alimentación del ganado.

\section{CONCLUSIONES}

Los resultados de la presente investigación señalan que el sorgo negro forrajero debe cosecharse antes de los tres meses para obtener la mayor concentración de nutrientes. Cuando el objetivo del productor sea aprovechar o conservar la máxima cantidad de forraje, la mayor cosecha se logra a los 133 días, con una cantidad de proteína cercana al $8 \%$ y un contenido de fibra neutro detergente de $77 \%$, aceptables aún para la conservación mediante ensilaje.

\section{LITERATURA CITADA}

ALFARO, O.L. 1988. Evaluación de la producción y calidad del sorgo negro forrajero (Sorghum almum) a través de diferentes distancias de siembra, densidades de siembra y niveles de fertilización nitrogenada. Tesis de Ingeniero Agrónomo. Escuela de Zootecnia, Universidad de Costa Rica. 107 p.

AMADOR, A.L.; BOSCHINI, C. 2000. Calidad nutricional de la planta de sorgo negro forrajero (Sorghum almum) para alimentación animal. Agronomía Mesoamericana 11:79-84.

AOAC (Association of Official Analysis Chemistry). 2002. Animal feed. Washington D.C. EUA. Chapter 4, p.1.

BOSCHINI, C.; AMADOR, L.A. 2001. Degradabilidad ruminal de la planta de sorgo negro forrajero (Sorghum almum) en diferentes etapas de crecimiento. Agronomía Mesoamericana 12:169-174.

BOSCHINI, C.; ELIZONDO, J. 2003. Serie agrotecnológica No. 1. Curso teórico y práctico de ensilaje de forraje. Editorial de la Universidad de Costa Rica, San José, Costa Rica. 69 p.

CORRALES, J.C. 1986. Efecto de la densidad y distancia de siembra y la fertilización nitrogenada sobre la producción de biomasa y la calidad del sorgo negro forrajero 
(Sorghum almum). Tesis de Ingeniero Agrónomo. Escuela de Zootecnia, Universidad de Costa Rica, San José, Costa Rica. 173 p.

GOERING, H.K.; VAN SOEST, P.J. 1970. Forage fiber analysis (Apparatus, reagents, procedures and some applications). Agricultural Handbook No. 379. ARS-USDA, Washington, DC. 76 p.

HERNÁNDEZ, H.E. 1986. Fertilización nitrogenada y edad de corte para sorgo forrajero (Sorghum almum). Tesis de Ingeniero Agrónomo. Escuela de Zootecnia, Universidad de Costa Rica., San José, Costa Rica. 145 p.

JIMÉNEZ, C.A. 1995. Degradabilidad ruminal del sorgo negro forrajero (Sorghum almum), Tesis de Maestría en Nutrición Animal. Programa en Ciencias Agrícolas y Recursos Naturales, Universidad de Costa Rica., San José, Costa Rica 61 p.

McDONALD, P. 1981. The biochemistry of silage. John Wiley \& Sons. New York. USA. 226 p.

OWEN, F.G.; MOLINE, W.J. 1970. Sorghum for forage; Sorghum production and utilization. Wall \& Ross. Westport, Va. 320 p.
PEÑAGARICANO, J.A.; ARIAS, W.; LLANEZA, N.J. 1973. Ensilaje (manejo y utilización de las reservas forrajeras). Editorial Hemisferio Sur. Montevideo, Uruguay. 344 p.

SAS (Statistical Analysis System Institute Inc. USA). 1985 SAS User's Guide: Statistics (Version 5). Cary, NC. 86 p.

VAN SOEST, P.J. 1982. Nutritional ecology of the ruminant. Ruminant metabolism, nutritional strategies, the cellulolytic fermentation and the chemistry of forages and plant fibers. O \& B books, inc. USA. 374 p.

VASQUEZ, A. 1982. Estudio detallado de los suelos de la Estación Experimental de Ganado Lechero El Alto. Escuela de Fitotecnia, Facultad de Agronomía, Universidad de Costa Rica, San José, Costa Rica. p. 36.

VILLEGAS, O. 1990. Producción y valor nutritivo de sorgos forrajeros y sus ensilados a diferentes edades de cosecha. Tesis de Ingeniero Agrónomo. Sede Regional de Guanacaste, Universidad de Costa Rica., Guanacaste, Costa Rica. 84 p. 